\title{
Effects of overtraining on extinction in newts (Cynops pyrrhogaster)
}

\author{
$\operatorname{AUTHOR}(S)$ :
}

Shibasaki, Masahiro; Ishida, Masato

\section{CITATION:}

Shibasaki, Masahiro ...[et al]. Effects of overtraining on extinction in newts (Cynops pyrrhogaster). Journal of comparative psychology 2012, 126(4): 368-371

ISSUE DATE:

2012-11

URL:

http://hdl.handle.net/2433/172545

\section{RIGHT:}

(C) 2012 American Psychological Association; この論文は著者最終稿で す。内容が印刷版と異なることがありますので、引用の際には出版社 版をご確認ご利用ください。This is the Accepted Author Manuscript. Please cite only the published version. 
Running Head: LEARNING IN NEWTS

Effects of Overtraining on Extinction in Newts (Cynops pyrrhogaster)

Masahiro Shibasaki ${ }^{1}$ and Masato Ishida ${ }^{2}$

${ }^{1}$ Japan Society for the Promotion of Science; Primate Research Institute, Kyoto University, Japan

${ }^{2}$ Department of Psychology, Osaka University of Education, 4-698-1 Asahigaoka, Kashiwara, Osaka 582-8582, Japan

This research was completed while the first author was at Osaka University of Education.

Correspondence concerning this article should be addressed to Masahiro Shibasaki, Primate Research Institute, Kyoto University, Kanbayashi, Inuyama 484-8506, Japan. E-mail: zenkou@pri.kyoto-u.ac.jp 


\section{Effects of Overtraining on Extinction in Newts (Cynops pyrrhogaster)}

\section{Abstract}

The over-training extinction effect (OEE), a phenomenon in which extended training facilitates extinction, has been found in mammals and reptiles. Fish, however, have never shown OEE. No study has yet investigated OEE in newts, a representative amphibian species. We tested whether newts, Cynops pyrrhogaster, show OEE in a straight-alley task. All animals received five trials per day and were given a piece of dried worm during reinforced trials. They showed significant acquisition and extinction effects in both reinforced and nonreinforced trials. However, we found no difference in extinction performance between a group with 25 -trial acquisition and one with 75 -trial acquisition, suggesting that OEE was not found in newts. OEE has generally been explained in terms of frustration-related mechanisms. Our results suggest that emotional reactions to nonreward, such as frustration, may not influence behavior in amphibians. Keywords: over-training extinction effect, successive acquisitions and extinctions, frustration, newts 
In this study, we examine one of the paradoxical phenomena of learning, the overtraining-extinction effect (OEE). OEE is defined as the facilitation of extinction by extended post-criterion training. The effect was reported first by North and Stimmel (1960), who trained rats in a runway and demonstrated faster extinction in groups given 90 or 135 reinforcement trials than in a group given 45 trials. Traditional learning theories (e.g., Hull, 1943) hypothesize that habit strength increases as a function of the number of training trials and that resistance to extinction is a direct function of habit strength. Overtraining, according to these models, should increase both habit strength and concomitant resistance to extinction. However, OEE contradicts this prediction.

Most experiments on OEE have been conducted with rats, and few reports are available using other animals. Ishida and Papini (1997) trained turtles in a runway and found reduced resistance to extinction in groups given 140 or 210 reinforcement trials compared with a group given 70. However, Muzio, Ruetti, and Papini (2006) trained toads in a runway and found no differences in extinction between the group given 10 reinforcement trials and the group given 30. Ishida (1977) trained goldfish in a runway, and also showed no extinction differences between the group given 24 reinforcement trials and the group given 72 .

Theios and Brelsford (1964) explained the mechanism of OEE based on Spence (1956) and Amsel (1962) as follows: habit strength is a function of the number of training trials, and so is resistance to extinction. Furthermore, incentive motivation is a direct function of the number of rewards, and emotional reactions (i.e., frustration) to nonreward trials are a simple reflection of the magnitude of incentive motivation. The greater the level of frustration becomes, the lower the resistance to extinction of the instrumental response should be. According to Theios and Brelsford (1964), the occurrence of OEE depends on the subjects' frustration at the shift from reinforcement 
trials to extinction trials, suggesting that animals that show OEE are capable of experiencing frustration (Amsel, 1962).

Amphibians, the first vertebrates to have gained a measure of independence from the aquatic environment, spend a substantial portion of their existence on land (Macphail, 1982). Living amphibians are assigned to three orders, the Anura (frogs and toads, of which there are some 4380 species), the Urodela (newts and salamanders, with 430 species), and the Gymnophiona (about 160 species) (Matsui, 2006). Most studies on amphibian learning have used anurans, and studies on urodeles are still insufficient to draw generalized conclusions (Ellins, Cramer, \& Martin, 1982; Papini, 1997). The present experiment was designed to test OEE under massed-trial conditions in Japanese fire-bellied newts, Cynops pyrrhogaster. OEE has not been previously reported in amphibians under a massed-trial condition. In addition to test OEE, we examined the effect of successive acquisitions and extinctions (SAE) to compare with the results of SAE in goldfish (Ishida, 1977).

Amphibians are said to be difficult to train in experimental settings (Ellins et al., 1982; Hodos \& Campbell, 1969; Thompson \& Boice, 1975). In fact, they are relatively unresponsive to solid food; this is often attributed to the limited effects of deprivation on lethargic animals that feed infrequently (Goldstein, 1960; Suboski, 1992). However, our preliminary experiments showed that Japanese fire-bellied newts could be trained using a piece of dried worm as a reinforcer.

\section{Method}

Subjects. The subjects were 24 experimentally naïve adult fire-bellied newts, Cynops pyrrhogaster, obtained from a commercial dealer in Shizuoka, Japan. In this experiment, female newts were used because of their larger size and greater appetite compared with males. The length of the newts was about $100 \mathrm{~mm}$ on average. They 
were provided with dried-worm meal for 10 min once a day.

Apparatus. The newts were trained in a runway made of gray polyvinyl-chloride board. The runway was $550 \mathrm{~mm}$ long, $50 \mathrm{~mm}$ wide, and $50 \mathrm{~mm}$ high, and it was filled with water to a depth of $15 \mathrm{~mm}$. The runway had three main divisions: a start box (150 $\mathrm{mm}$ long), an alley (250 $\mathrm{mm}$ long), and a goal box (150 $\mathrm{mm}$ long). The alley was separated from the start and goal box by manually operated guillotine doors. A lid made of wire net was installed in the upper part of the apparatus to prevent the animals from escaping. The apparatus was illuminated from $600 \mathrm{~mm}$ above the apparatus with a 15 $\mathrm{W} / \mathrm{m}^{2}$ fluorescent lamp, and the sound of an exhaust fan served as white noise. The temperature of the laboratory was kept at about $23^{\circ} \mathrm{C}$.

Procedure. Prior to the experimental training, pretraining was carried out for two days. On the first day, newts were placed in the start box and allowed to move freely in the apparatus. On the second day, when they reached the goal box, the guillotine door was closed and the subjects were fed a piece of dried worm (about $10 \mathrm{mg}$ ), which was also offered during acquisition training. If a newt failed to enter the goal box within 10 min, the animal was gently guided there by an experimenter's hand and then given a piece of dried worm. After the pretraining, the subjects were divided randomly into two groups (Group-N and Group-O).

One training session was given per day, and each consisted of five trials. Group-O received continuous reinforcement from the first to the $15^{\text {th }}$ day ( 75 trials) and then received extinction training from the $16^{\text {th }}$ to the $20^{\text {th }}$ day ( 25 trials). Group- $\mathrm{N}$ received continuous reinforcement ( 25 trials) from the first to the fifth day, then received non-reward sessions from the $6^{\text {th }}$ to the $10^{\text {th }}$ day ( 25 trials, extinction $\mathrm{I}$ ), then received continuous reinforcement again from the $11^{\text {th }}$ to the $15^{\text {th }}$ day (25 trials), and finally received extinction training from the $16^{\text {th }}$ to the $20^{\text {th }}$ day (25 trials, extinction $\mathrm{II}$ ). This 
experimental design is the same as that used by Ishida (1977) using goldfish as subjects. We tested OEE by comparing performance in Group-N's first extinction trials with Group-O's extinction trials. SAE was tested from comparing Group-N's extinction I trials with extinction II trials.

Each trial started when an animal was placed in the start box, and $10 \mathrm{~s}$ later, the two guillotine doors were opened simultaneously. When the animal passed through more than the half of the alley, the guillotine door of the start box was gently closed to prevent the animal from going back. Once the animal entered the goal box entirely, the guillotine door of the goal box was closed. Running latency was defined as the duration from the opening of the start-box guillotine door to the closing of goal-box door and was measured by a stop watch. If the animal failed to enter the goal box with all four legs within $120 \mathrm{~s}$ after the guillotine doors were opened, a running latency of $120 \mathrm{~s}$ was assigned for that trial, and the animal was gently guided by hand to the goal box. During reinforced trials, newts were given a piece of dried worm with tweezers following entry into the goal box, but no such reward was given during extinction (or nonreward) trials. During reinforced trials, newts remained in the goal box until they ate the worm, and they were kept for $10 \mathrm{~s}$ during extinction trials. The animals were then taken out of the goal box and replaced in the start box to initiate the next trial. The inter-trial interval was about $10 \mathrm{~s}$. The basic procedure of the extinction trials was almost the same as that for the reinforced trials. In the extinction trials, subjects were fed 5 pieces of dried worm in their home tanks at least $30 \mathrm{~min}$ after the end of the experimental session.

Results

Twelve newts were removed during the course of experiment because of immobility or disinterest in the food. Only 12 subjects (six subjects in each group) were available for analyses. The running latencies were transformed to a $\log 10$ scale to 
improve normality. The transformed latencies were then analyzed using conventional analysis of variance in which trial was a repeated-measure factor. Figure 1 shows the performance of the two groups during acquisition and extinction training. On the first day of acquisition, the Group $\times$ Trial analysis of variance indicated no significant main effect of Group, $F(1,10)=2.29, p=.16, \eta_{p}^{2}=.19$. During the first five sessions of the acquisition training, the latencies of both groups decreased linearly. The Group $x$ Session analysis of variance indicated a significant main effect of Session, $F(4,40)=$ $7.97, p<.001, \eta_{\Gamma}^{2}=.89$, but neither the main effect of Group, $F(1,10)=0.03, p=.87$, $\eta_{\mathrm{p}}^{2}=.003$, nor the interaction effect, $F(4,40)=0.56, p=.69, \eta_{\mathrm{p}}^{2}=.05$, was significant.

It was of interest to determine whether acquisition and extinction could be observed on the first trial of each session because such a result would indicate that acquisition was not entirely dependent on carry-over stimuli from prior trials (Muzio, Segura, \& Papini, 1992). The Group $\times$ Session analysis of variance indicated that neither the main effect of Group, $F(1,10)=0.005, p=.94, \eta_{p}^{2}=.0005$, nor the interaction effect, $F(4,40)=1.26, p=.30, \eta_{\Gamma}^{2}=.11$, was significant. However, the main effect of Session was significant, $F(4,40)=4.97, p<.005, \eta_{\mathrm{p}}^{2}=.33$. These results indicate that acquisition in this situation cannot be entirely reduced to carry-over effects operating within each session.

In the next five days (sessions 6 to 10 ), the response latencies of Group-N increased greatly because they were receiving extinction training. The Group $\times$ Session analysis of variance indicated a significant main effect of Group, $F(1,10)=6.32, p$ $<.05, \eta_{\mathrm{p}}^{2}=.39$, but neither the main effect of Session, $F(4,40)=0.71, p=.59, \eta_{\mathrm{p}}^{2}=.07$, nor the interaction effect, $F(4,40)=1.03, p=.41, \eta_{\mathrm{p}}^{2}=.09$, was significant. During the $11^{\text {th }}$ to $15^{\text {th }}$ sessions, the latencies of Group-N decreased, as they were receiving continuous reinforcement again. The Group $\times$ Session analysis of variance showed no 
significant effect of Group, $F(1,10)=0.002, p=.96, \eta_{\mathrm{p}}^{2}=.0002$, of Session, $F(4,40)=$ $0.40, p=.81, \eta_{\mathrm{p}}^{2}=.04$, or of the interaction, $F(4,40)=0.41, p=.80, \eta_{\mathrm{p}}^{2}=.04$.

$O E E$. Although the Group $\times$ Trial analysis of variance indicated no significant main effect of Group when comparing Group-N's performance on the fifth day with Group-O's on the $15^{\text {th }}$ day, $F(1,10)=0.85, p=.38, \eta_{\mathrm{p}}^{2}=.29$, individual response rates were highly variable. In addition, Figure 1 shows that Group-N of the first acquisition training had not reached asymptotic running latencies. Consequently, the extinction data were examined with a rate transformation (Anderson, 1963). The Anderson's transformation corrected for different latencies at the end of acquisition. Each extinction score was corrected with the equation: rate corrected latency $=$ (extinction trial terminal latency) / (terminal acquisition - terminal latency), where terminal acquisition was the average of a subject's latencies on the last five trials of the last day of acquisition, extinction trial was the subject's latency on a given extinction trial, and terminal latency was assumed to be 2.08 (the $\log 10$ of $120 \mathrm{~s}$, which was the longest latency for a given extinction trial). The individual subject's transformed rates were averaged within groups and are plotted in Figure 2. The right panel (B) of Figure 2 shows the first extinction performance of Group- $\mathrm{N}$ and extinction performance of Group-O. A Group $\times$ Session analysis of variance comparing them showed no significant main effect of Group, $F(1,10)=0.79, p=.40, \eta_{\mathrm{p}}^{2}=.07$, and no significant interaction effect, $F(4,40)=1.10, p=.37, \eta_{\mathrm{p}}^{2}=.10$. That is to say, over-training did not accelerate extinction, and OEE was not found.

$S A E$. The left panel (A) of Figure 2 shows performance during the first and the second extinction of Group- $\mathrm{N}$ in a comparable manner. Resistance to extinction did not differ significantly between them, $F(1,5)=0.02, p=.90, \eta_{\mathrm{p}}^{2}=.004$, and the first extinction did not cause any acceleration effect during the second extinction. In the 
results, the latencies of both groups increased at almost the same pace during the extinction period from the $16^{\text {th }}$ day to the $20^{\text {th }}$ day. A Group $\times$ Session analysis of variance showed no significant Group, $F(1,10)=0.95, p=.35, \eta_{\mathrm{p}}^{2}=.09$, or interaction effect, $F(4,40)=0.49, p=.74, \eta_{\mathrm{p}}^{2}=.05$.

\section{Discussion}

We tested whether an amphibian, Cynops pyrrhogaster, showed OEE in a runway task. Newts showed significant acquisition and extinction effects in the reinforced and nonreinforced trials. However, we found no difference in extinction performance between the group with 25-trial acquisition and that with 75-trial acquisition (over-training), and the first extinction did not cause any acceleration effect during the second extinction in Group-N. As same as the results of goldfish (Ishida, 1977), neither OEE nor SAE occurred in newts.

OEE has been found in runway experiments involving rats (North \& Stimmel, 1960) and turtles (Ishida \& Papini, 1997), but not in toads (Muzio et al., 2006) and goldfish (Ishida, 1977). The former and the latter animal groups differ in terms of other behavioral features. Signs of emotion (e.g., emotional fever, emotional tachycardia, signs of the use of sensory pleasure to resolve motivational conflicts, and the ability to learn flavor aversion) have been found in several mammals, birds, and reptiles, but not in amphibians and fish (Balasko \& Cabanac, 1998; Cabanac, 1999; Cabanac \& Aizawa, 2000; Cabanac \& Bernieri, 2000; Cabanac \& Cabanac, 2000; Cabanac, Cabanac, \& Parent, 2009; Cabanac \& Gosselin, 1993; Paradis \& Cabanac, 2004). Studies of comparative anatomy suggest that the amygdala participates in emotional learning in mammals and that the advent of the basolateral amygdaloid complex and its reptilian equivalent brought genuine innovations to vertebrate emotional behavior (Laberge, Mühlenbrock-Lenter, Grunwald, \& Roth, 2006). If we take into consideration the fact 
that OEE is related to emotions such as frustration (Amsel, 1992), the absence of a basolateral complex in amphibians would predict the absence of OEE in amphibians.

In the present experiment, a fair number of newts ceased to ingest reward food during acquisition training. This is in accord with the observation that amphibians are unresponsive to the food and difficult to train (Ellins et al., 1982; Jenkin \& Laberge, 2010; Suboski, 1992). The cause of unresponsiveness to reinforcers cannot be a lack of habituation to the apparatus, given that subjects ingested reinforcers during early training sessions. Davis and Singer (1967) reported that tiger salamanders, Ambystoma tigrinum, have advantages such as ease of maintenance, a voracious appetite, and a high level of activity for amphibians. Moreover, Ellins et al. (1982) reported that adult spotted newts, Triturus viridescens, could be trained using water as a reinforcer. These species seem to be practical laboratory animals for use in research on tailed amphibian learning. 


\section{Acknowledgements}

The preparation of this manuscript was partially supported by Grant-in-Aid for JSPS

Fellowship (No. 23/5358) to Masahiro Shibasaki. We are grateful to Dr. Nobuyuki

Kawai for helpful comments on an earlier version of this manuscript. 


\section{References}

Amsel, A. (1962). Frustrative nonreward in partial reinforcement and discrimination learning: Some recent history and a theoretical extinction. Psychological Review, 69, 306-328.

Amsel, A. (1992). Frustration theory. Cambridge, UK: Cambridge University Press.

Anderson, N. H. (1963). Comparison of different populations: Resistance to extinction and transfer. Psychological Review, 70, 162-179.

Balasko, M., \& Cabanac, M. (1998). Behavior of juvenile lizards (Iguana iguana) in a conflict between temperature regulation and palatable food. Brain Behavior and Evolution, 52, 257-262.

Cabanac, M. (1999). Emotion and phylogeny. Japanese Journal of Physiology, 6, 176-190.

Cabanac, M., \& Aizawa, S. (2000). Fever and tachycardia in a bird (Gallus domesticus) after simple handling. Physiology and Behavior, 69, 541-545.

Cabanac, M., \& Bernieri, C. (2000). Behavioral rise in body temperature and tachycardia by handling of a turtle (Clemmys insculpta). Behavioural Processes, $49,61-68$.

Cabanac, A., \& Cabanac, M. (2000). Heart rate response to gentle handling of frog and lizard. Behavioural Processes, 52, 89-95.

Cabanac, M., Cabanac, A. J., \& Parent, A. (2009). The emergence of consciousness in phylogeny. Behavioural Brain Research, 198, 267-272.

Cabanac, M., \& Gosselin, F. (1993). Emotional fever in the lizard Callopistes maculatus (Teiidae). Animal Behaviour, 46, 200-202.

Cabanac, M., \& Laberge, F. (1998). Fever in goldfish is induced by pyrogens but not by handling. Physiology and Behavior, 63, 377-379. 
Davis, S. F., \& Singer, J. J. (1967). The acquisition and extinction of instrumentally conditioned approach behavior in the tiger salamander (Ambystoma tigrinum). Psychonomic Science, 8, 383-384.

Ellins, S. R., Cramer, R. E., \& Martin, G. C. (1982). Discrimination reversal learning in newts. Animal Learning \& Behavior, 10, 301-304.

Goldstein, A. C. (1960). Starvation and food-related behavior in a poikilotherm, the salamander, Triturus viridescens. Journal of Comparative and Physiological Psychology, 53, 144-150.

Hodos, W., \& Campbell, C. B. G. (1969). Scala naturae: Why there is no theory in comparative psychology. Psychological Review, 76, 337-350.

Hull, C. L. (1943). Principles of behavior. New York: Appleton-Century-Crofts.

Ishida, M. (1977). Effects of partial reinforcement and overtraining in the goldfish. Annual of Animal Psychology, 27, 79-85.

Ishida, M., \& Papini, M. R. (1997). Massed-trial overtraining effects on extinction and reversal performance in turtles (Geoclemys reevesii). Quarterly Journal of Experimental Psychology, 50B, 1-16.

Jenkin, S. \& Laberge, F. (2010). Visual discrimination learning in the fire-bellied toad Bombina orientalis. Learning \& Behavior, 38, 418-425.

Laberge, F., Mühlenbrock-Lenter, S., Grunwald, W., \& Roth, G. (2006). Evolution of the amygdala: New insights from studies in amphibians. Brain Behavior and Evolution, 67, 177-187.

Macphail, E. M. (1982). Brain and intelligence in vertebrates. Oxford, England: Clarendon Press.

Matsui, M. (2006). Diversity and evolution of vertebrates. Tokyo: Shokabo.

Muzio, R. N., Ruetti, E., \& Papini, M. R. (2006). Determinants of instrumental 
extinction in terrestrial toads (Bufo arenarum). Learning and Motivation, 37, $346-356$.

Muzio, R. N., Segura, E. T., \& Papini, M. R. (1992). Effect of schedule and magnitude of reinforcement on instrumental learning in the toad,Bufo arenarum. Learning and Motivation, 23, 406-429.

North, A. J., \& Stimmel, D. T. (1960). Extinction of an instrumental response following a large number of reinforcements. Psychological Reports, 6, 227-234.

Papini, M. R. (1997). Role of reinforcement in spaced-trial operant learning in pigeons (Columba livia). Journal of Comparative Psychology, 111, 275-285.

Paradis, S., \& Cabanac, M. (2004). Flavor aversion learning induced by lithium chloride in reptiles but not in amphibians. Behavioural Processes, 67, 11-18.

Spence, K. W. (1956). Behavior theory and conditioning. New Haven: Yale University Press.

Suboski, M. D. (1992). Releaser-induced recognition learning by amphibians and reptiles. Animal Learning \& Behavior, 20, 63-82.

Theios, J., \& Brelsford, J. (1964). Overtraining extinction effect as an incentive phenomenon. Journal of Experimental Psychology, 67, 463-467.

Thompson, P. A., \& Boice, R. (1975). Attempts to train frogs: Review and experiments. Journal of Biological Psychology, 17, 3-13. 


\section{Figure Legends}

Figure 1. Mean Log Latency in the series of acquisition and extinction of the two groups. Error bars depict S.E.Ms.

Figure 2. Successive extinction (A) and the effect of overtraining on extinction (B) (T represents the terminal level of acquisition). Error bars depict S.E.Ms. 


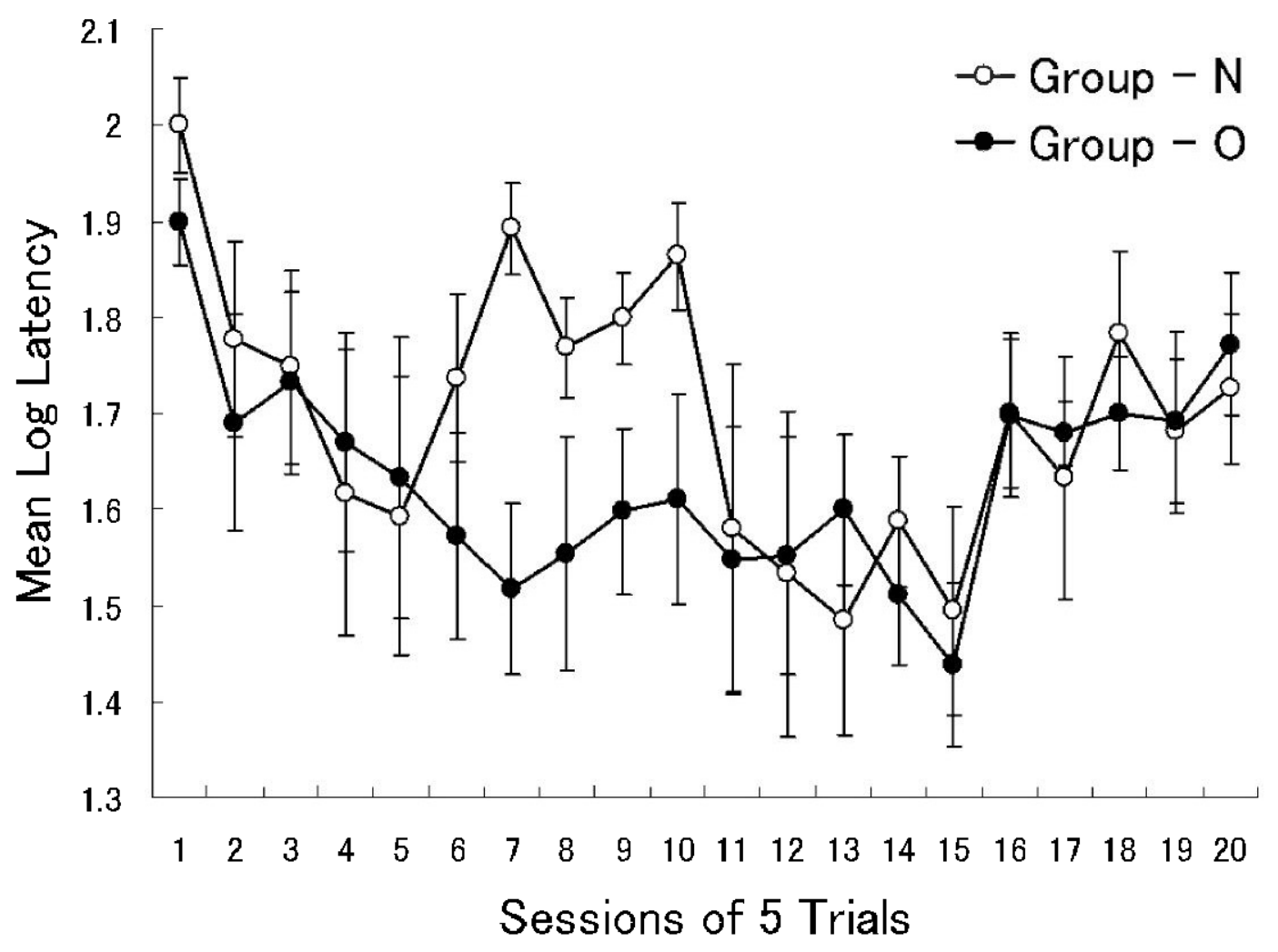

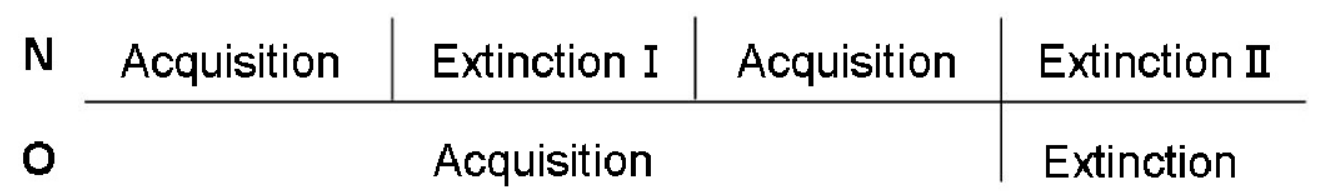




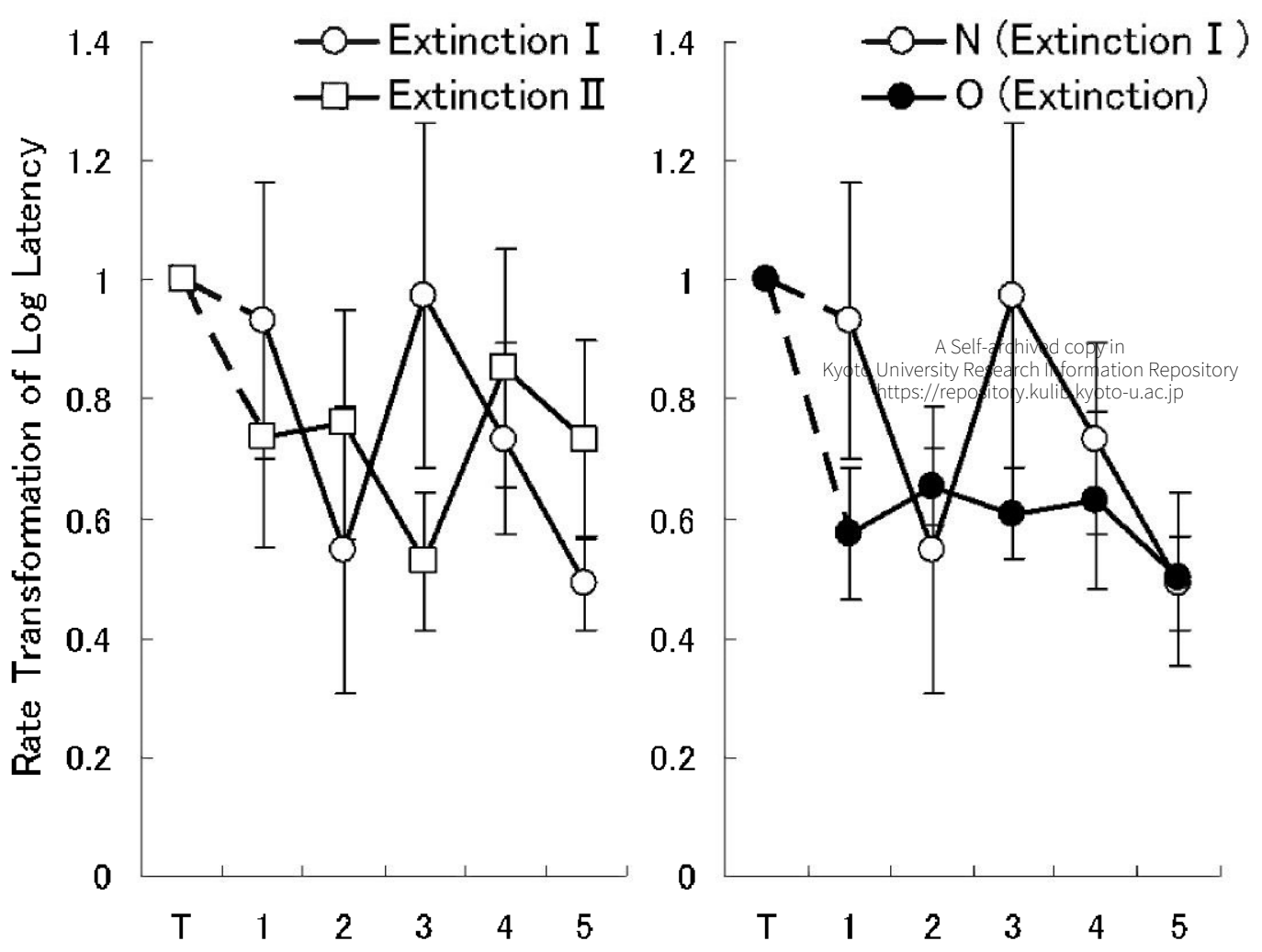

